\title{
La lengua en la construcción de la identidad nacional uruguaya en Juan Zorrilla de San Martín: la nación hispánica y la nación subtropical atlántica
}

\author{
Mariela Oroño ${ }^{1}$ \\ Universidad de la República/Instituto de Lingüistica/ Uruguay
}

\begin{abstract}
Resumen
En este trabajo estudio las representaciones sociolingüísticas en artículos de prensa, conferencias y discursos del literato uruguayo Juan Zorrilla de San Martín (1855-1931), un intelectual destacado de la generación del 80 en Uruguay y referente cultural de la nacionalidad, escritos durante el período de construcción estatal en el último cuarto del siglo XIX. En sus discursos se preocupó por crear un carácter nacional que diferenciara a Uruguay de España y el resto de los países hispanoamericanos, pero sin perder el vínculo y la identidad hispanos. En particular llamo la atención sobre dos representaciones nacionalistas que aparecen en sus discursos con las siguientes denominaciones y en las que la lengua ocupa un lugar importante: nación hispánica y nación subtropical atlántica.
\end{abstract}

Palabras clave: Uruguay, Juan Zorrilla de San Martín, representaciones sociolingüísticas, identidad nacional.

\footnotetext{
1 Para correspondencia, dirigirse a: Mariela Oroño (marielaor@vera.com.uy), Facultad de Humanidades y Ciencias de la Educación, Instituto de Lingüística, Avenida Uruguay 1695, código postal 11.200, Montevideo (Uruguay).
} 
THE LANGUAGE IN THE CONSTRUCTION OF THE URUGUAYAN NATIONAL identity in Juan Zorrilla de San Martín: NACIÓN HISPÁNICA AND NACIÓN SUBTROPICAL ATLÁNTICA

\begin{abstract}
In this paper I study the sociolinguistic representations in press articles, conferences and discourses of the Uruguayan writer Juan Zorrilla de San Martín (1855-1931), a prominent intellectual of the generation of 80 in Uruguay and cultural referent of the nationality, written in the State construction period in the late Nineteenth century. In his speeches he was concerned to create a national character that would differentiate Uruguay from Spain and the rest of the SpanishAmerican countries, but without losing the ties and the Hispanic identity. In particular I study two nationalist representations that appear in their speeches with the denominations Hispanic nation and Atlantic subtropical nation.
\end{abstract}

Keywords: Uruguay, Juan Zorrilla de San Martín, sociolinguistic representations, national identity.

Recibido: 28/11/17 Aceptado: 30/04/18

\title{
1. INTRODUCCIÓN
}

El lenguaje es un objetivo y un instrumento privilegiado en la construcción de identidades. En este proceso participan las representaciones sociales, que se constituyen, reproducen y legitiman a través de discursos públicos e institucionales; entre ellos, los discursos de los intelectuales. En el caso particular de las identidades nacionales, los discursos públicos e institucionales transmiten representaciones nacionalistas y puristas, dentro de las que ocupan un lugar destacado las representaciones sobre el lenguaje, en la medida en que la lengua tiene un papel fundamental como referente de la nacionalidad.

Las representaciones sociolingüisticas (Boyer 2003) son representaciones sociales que involucran ideas socialmente compartidas acerca de una lengua. Como señalan Narvaja de Arnoux y Del Valle (2010: 3), "por un lado, se refieren a objetos lingüísticos (lenguas, variedades, hablas, acentos, registros, géneros, modos de leer o de escribir, etc.) y [...], por otro, implican evaluaciones sociales de esos objetos y de los sujetos con los que son 
asociados". Al vincular el orden lingüístico con el orden social, mostrando cómo se articulan, permiten comprender otros aspectos de la realidad social. En este sentido, las representaciones sociolingüísticas contribuyen a la formación de un imaginario comunitario (Boyer 2003).

La creación de las comunidades imaginadas llamadas naciones implicó el desarrollo de una conciencia nacional donde antes había otro tipo de conciencia, vinculada con la comunidad religiosa y el reino dinástico (Anderson 1993). "La ruptura de las conciencias anteriores y la creación de esta nueva conciencia [en tanto que imaginada], debió crear su propia narrativa" (Anderson 1993: 283). Los discursos públicos e institucionales juegan, así, un rol importante en la construcción de las identidades nacionales. Los relatos vinculados con nuestra nación crean representaciones sobre nosotros y sobre los demás, sobre lo que hacemos y sobre el sentido de nuestras acciones.

La lengua es un atributo importante de la identidad nacional, como expresión idiosincrática del espíritu nacional (Haugen 2001, Fishman 1989), como medio de difusión de las ideas nacionales y como organizadora del aparato burocrático del Estado (Anderson 1993, Hobsbawm 1992, Gellner 1988). La lengua es un referente privilegiado de la identidad nacional porque, además de su función comunicativa, cumple una función demarcativa (Fishman 1989, Zimmermann 2008), como indicador externo y elemento cohesivo interno de un grupo (Barrios 2009). Por eso la lengua nacional se ha interpretado como la única lengua legítima (Bourdieu 2001).

El nacionalismo lingüístico se vincula estrechamente con el purismo lingüístico, porque los defensores de las lenguas nacionales aspiran a su preservación, manteniéndolas libres de cambios y de elementos considerados exógenos o vulgares (Barrios 2011). El purismo lingüístico se relaciona estrechamente con la lengua estándar y los procesos de estandarización lingüística, con la prescripción idiomática y la ideología de la estandarización (Milroy y Milroy 1985), en la medida en que la prescripción implica tomar decisiones sobre los modelos de ejemplaridad.

En este trabajo ${ }^{2}$ estudio las representaciones sociolingüísticas en artículos de prensa, conferencias y discursos del literato uruguayo Juan Zorrilla de San Martín (1855- 1931) escritos durante el período de construcción estatal en el último cuarto del siglo XIX. En particular llamo la atención sobre

2 El estudio forma parte de mi investigación de doctorado en curso (Doctorado en Lingüística, UDELAR). 
dos representaciones nacionalistas que aparecen en sus discursos con las siguientes denominaciones: nación hispánica y nación subtropical atlántica.

El corpus está conformado por artículos de prensa publicados por Zorrilla de San Martín en el periódico El bien público de Montevideo (fundado por él mismo), discursos y conferencias dictados como representante diplomático del Estado uruguayo ante España, Portugal y el Vaticano, así como por otros discursos dictados como miembro destacado del Club Católico de Montevideo (muchos de los cuales fueron además publicados en El bien público). En total, se trata de dieciséis documentos escritos entre 1878 y 1905 en los que la lengua ocupa un lugar importante. Tengo en cuenta también otros documentos del autor para atender los intereses y preocupaciones vinculados con sus reflexiones sobre la lengua.

\section{EL AMBIENTE: EL ESTADO NACIONAL URUGUAYO Y LOS INTELECTUALES DE LA GENERACIÓN DEL 80}

Durante el período posterior a la independencia de España se generó en los países hispanoamericanos una discusión entre los intelectuales criollos sobre el estatus de las variedades americanas en relación con el español peninsular y las peculiaridades de las normas locales (Niño-Murcia 1997). La cuestión del arraigo (Gallardo 1978) del español se instaló como tema de discusión, más o menos conflictivo según cómo se interpretara el vínculo con la tradición peninsular y más o menos presente según los contextos sociohistóricos. El desafío de los intelectuales hispanoamericanos fue precisamente fundar una nueva tradición que les permitiera redefinir el arraigo del español en los estados recién independizados.

Durante el período de construcciones de las identidades nacionales de los países hispanoamericanos, las posiciones sobre la lengua española reflejaron el modo de resolver el vínculo político tanto entre ellos como con España. En este sentido, la discusión entre americanistas e hispanistas es un punto de partida importante para la construcción de las identidades de los países hispanoamericanos. Muestra la tensión política del momento histórico que se estaba viviendo. Los americanistas, con adhesión al romanticismo al comienzo, desarrollaron un discurso crítico y de ruptura con lo español. Los hispanistas, en cambio, defendían la existencia de una civilización hispana con centro hegemónico en España, cuyos valores y tradiciones cristalizaban 
en la lengua castellana (Niño-Murcia 1997, Del Valle y Gabriel- Stheeman 2004, Asencio 2004).

En el caso de Uruguay, la élite intelectual también tuvo un lugar destacado en la conformación de la nacionalidad. La discusión sobre la lengua vinculada a cuestiones nacionalistas y normativas evidenció la necesidad de diferenciarse de España, pero también de los países vecinos (Brasil y Argentina), como reflejo de las condiciones que condujeron a la creación del estado uruguayo (Caetano 1992). La demarcación de fronteras políticas y lingüísticas, así como la homogeneización cultural y lingüística tuvieron especial importancia durante el período de modernización, a fines del siglo XIX (Behares 2007).

Durante el primer período de construcción del Estado nacional uruguayo, los intelectuales de la generación del 80 (Zum Felde 1967) fueron la élite que actuó en los planos educativo, histórico, de las artes plásticas y literario para crear el imaginario nacional fundamental del país, con figuras destacadas en cada uno de los campos mencionados: José Pedro Varela, Francisco Bauzá, Eduardo Acevedo Díaz, Juan Manuel Blanes y Juan Zorrilla de San Martín. Ellos "pensaron los marcos y mitos esenciales del Uruguay" (Ferré 1991 en Caetano et al. 2000: 21). En cuanto a la adscripción de estos intelectuales a las corrientes ideológicas americanista e hispanista, integraban la primera Andrés Lamas, Alejandro Magariños Cervantes y José Pedro Varela ${ }^{3}$, y la segunda Juan Zorrilla de San Martín (Rama 1982).

Este período "es de profunda remoción de ideas y creencias en el orden espiritual. Centros, diarios, revistas, folletos, libros, se renuevan entonces o se fundan, o se publican, para servir de escenario o de armas en una contienda que multiplica sus escaramuzas y diversifica sus frentes" (Ardao 1971: 94). Cuatro fuerzas aparecieron en conflicto: el catolicismo, el protestantismo, el racionalismo espiritualista y el positivismo, que dieron lugar a una gran lucha filosófico-religiosa entre los intelectuales de la época (Ardao 1971).

Particular enfrentamiento hubo entre católicos y racionalistas. La iglesia nacional, encabezada por el obispo Jacinto Vera y con orientación jesuita y tradicional, se enfrentó en primer lugar al racionalismo espiritualista, que se

\footnotetext{
La posición de los americanistas uruguayos no fue sin embargo muy radical. En Uruguay la separación lingüística de España no se propuso nunca como alternativa válida (Asencio 2004), salvo en algunos géneros del discurso literario, como la gauchesca (Rocca 2003).

Para un estudio sobre los americanistas románticos de la generación del 40 uruguayos y su vínculo con los de la generación del 37 argentina, cfr. Rocca 2003, Asencio 2004, Sansón 2006 y Bertolotti y Coll 2012.En particular sobre los debates sobre la lengua, cfr. entre otros Niño-Murcia (1997), Di Tullio (2003), Asencio (2004) y Bertolotti y Coll (2012).
} 
extendió en Uruguay entre 1865 y 1880 (Ardao 1971). Los católicos, entre los que se destacaban Mariano Soler, Francisco Bauzá y Juan Zorrilla de San Martín, se nuclearon en el Club Católico, la Unión Católica y el Liceo de Estudiantes Universitarios (fundados por iniciativa de Soler en 1875 y 1876, respectivamente) y difundieron sus ideas a través del diario El bien público (órgano oficial del Directorio de la Unión Católica), dirigido por Zorrilla de San Martín (Ardao 1971, Zum Felde 1967). Este diario fue el único periódico católico frente a una abundante prensa adversaria, entre la que se destacaban El siglo y La razón, este último periódico, racionalista.

Además de expresarse por medio de La razón, los racionalistas se reunían en el Club Racionalista (entre 1872 y 1877) y en el Ateneo de Uruguay (fundado en 1878) (Ardao 1971). Entre los racionalistas liberales del Ateneo se destacaban, Manuel Otero, Prudencio Vásquez y Vega y Daniel Muñoz, Carlos María Ramírez, José Pedro Varela (hasta fines de los 60), Francisco Berra, Eduardo Acevedo Díaz, José Enrique Rodó y Carlos Vaz Ferreira.

Desde el púlpito de El Bien público, Zorrilla polemizó sobre educación, religión y política con las personalidades de El Ateneo y en particular con Daniel Muñoz, director del diario La razón. Fueron también frecuentes las polémicas con el Inspector Nacional de Instrucción Primaria, José Pedro Varela (y sus sucesores), por la cuestión de la educación religiosa en las escuelas públicas.

A propósito de estos debates, Zorrilla de San Martín enfatizaba en el sexto aniversario del diario:

Seis años llevamos de constante lucha, durante los cuales jamás hemos rehuido una polémica; jamás hemos dejado sin contestación un argumento en contra de nuestra causa [...]; recta ha sido la intención decidida de esfuerzo e incondicional sacrificio en aras de la causa de Dios y de la patria (Zorrilla de San Martín 1884c).

En los periódicos mencionados, además de discusiones políticas, religiosas y filosóficas, aparecen reflexiones sobre la relación entre lenguaje y Estado nacional, que se insertan en los debates entre hispanistas y americanistas ya referidos.

La proliferación de todos estos discursos y debates, así como de la prensa escrita en general, muestra la relevancia que esta estaba adquiriendo como legitimadora del conocimiento social (Halperin Donghi 2013, Altamirano 2008, Burke 2002) y de sus hacedores principales -los intelectuales-en la formación, gestión y circulación de dicho conocimiento, incluyendo el caso del nacionalismo y la identidad nacional (Boyer y Lomnitz 2005). 


\section{EL AUTOR: JUAN ZORRILLA DE SAN MARTÍN}

Juan Zorrilla de San Martín (1855-1931; poeta, ensayista, periodista, abogado, político, diplomático, docente y académico), como ya se ha adelantado, fue un intelectual destacado de la generación del 80 en Uruguay y referente cultural de la nacionalidad. Aunque se formó en el exterior desde muy pequeño y se incorporó a la vida intelectual del Uruguay recién a su retorno al país en 1878, rápidamente pasó a formar parte de la renovación dirigente del catolicismo uruguayo, fundando El bien público ese mismo año.

En 1879 obtuvo la Cátedra de Literatura de la Universidad de Montevideo (actual Universidad de la República), de la que fue destituido en 1885 por enfrentamientos con el gobierno de Máximo Santos. Ese mismo año fue nombrado miembro correspondiente extranjero de la Real Academia Española (RAE), "dando así testimonio de apreciar justamente los conocimientos de V.S. en lingüística y en letras humanas" (Ibáñez 1956: 37), según se expresaba en la carta de notificación de su nombramiento 4 . Cuando décadas más tarde, en 1923, se creó por disposición de la RAE la Academia Uruguaya de la Lengua Española Correspondiente de la Real Academia Española, Zorrilla de San Martín fue nombrado su presidente (Asencio 2006, Barrios 2011).

En 1891 fue nombrado Ministro Plenipotenciario ante España y Portugal, con misión de representar al país en las fiestas que España preparaba para celebrar el cuarto centenario del descubrimiento de América. En 1897 también fue designado por el gobierno uruguayo como representante extraordinario ante el Vaticano, para tratar la creación de los nuevos obispados en Uruguay. En 1898 volvió al país y pasó a ocupar interinamente la cátedra de Derecho Internacional Público en la Universidad. Desde 1905

4 A propósito, resulta interesante por su actualidad el pedido que hizo el delegado ejecutivo de la Unión Ibero Americana a Zorrilla de San Martín, apelando a su vínculo con la RAE. En una carta que el delegado le escribió, fechada el 21 de junio de 1887, y publicada en El bien público el 7 de octubre del mismo año, decía: "Mucho han hecho y seguirán haciendo otras Academias y Sociedades por la confraternidad de la raza iberia; pero nosotros tomamos un rumbo quizá más práctico" (Zorrilla de San Martín 1887). Le proponía crear un centro correspondiente de la Unión Ibero Americana en Montevideo, para atender asuntos económicos. Porque "a la unión de las letras debía acompañar la unión de los intereses, del comercio, de la industria; la facilidad del cambio de los productos naturales de ambos pueblos, la protección mutua y eficaz. A eso tiende la Unión Ibero-Americana”. El interés en estrechar lazos económicos entre España y sus ex colonias a través de la lengua recuerda al actual discurso del Instituto Cervantes (por ejemplo, cfr. Del Valle 2007). 
y hasta su muerte en 1931 fue Delegado del Gobierno en el Departamento de Emisión del Banco de la República (Lauxar 1955).

Como puede observarse, Zorrilla de San Martín fue una voz autorizada no solo en el campo intelectual y literario (Bourdieu 2002) sino también en el político, lo que determina el alcance de sus discursos en la creación de las representaciones sobre el Estado y la lengua que conforman el imaginario nacional uruguayo.

Zorrilla de San Martín tuvo pleno reconocimiento en vida de su importancia como intelectual y referente de la nacionalidad. En 1879 leyó $L a$ leyenda patria en el acto de inauguración del monumento a la Independencia en la ciudad de Florida, consagrándose como el "poeta de la patria". Esta obra, que ha acompañado a muchas generaciones de escolares uruguayos en la celebración de las efemérides patrias, se constituyó en un clásico de la literatura nacional, al igual que Tabaré (1888) (Lauxar 1955, Bordoli 1961, Ramírez 2001).

Con La leyenda patria "el joven poeta se convirtió en portavoz lírico" (Rocca 2000: 242) de una necesidad que urgía a toda la clase dirigente: diferenciarse del Estado argentino ${ }^{5}$; aparecía la posibilidad de "dibujar un perfil distinto a los sucesos y los símbolos del otro lado del Plata" (Rocca 2003: 75) al tomar la figura del indígena como tópico literario al servicio del imaginario nacionalista (De Torres 2008, Rocca 2000) ${ }^{6}$. En Tabaré (1888), cuyo protagonista es el indio Tabaré, Zorrilla de San Martín transformó al charrúa en mito nacionalista (De Torres 2008). Al mistificar esta figura, Zorrilla legitimó las medidas tomados por el Estado en relación con esta población, y en particular el accionar de los grupos dirigentes que controlaban la representación nacional (Piazza 2011), porque al presentar al charrúa como un "mito", lo representaba como "algo perteneciente no al presente, sino al pasado, que debe ser venerado pero enterrado" (De Torres 2008: 87-88). De Torres explica que

5 Como señala Sansón (2006) también los historiadores de ambas márgenes se ocuparon de construir las diferencias entre los dos países.

6 Esto pudo ocurrir, por otra parte, porque a diferencia de lo que sucedía en Argentina, en Uruguay los indígenas no eran una amenaza real para el nuevo orden político y económico, sino un recuerdo. Alcanza con recordar los años del momento culminante del exterminio de las comunidades indígenas en cada país. La Conquista del desierto, liderada por Julio Argentino Roca, ocurrió entre 1878 y 1885, mientras que la Matanza del Salsipuedes, dirigida por Fructuoso Rivera, fue en 1831. Es decir, el indígena ingresó al imaginario nacionalista solo cuando desapareció. 
Zorrilla fue uno de los grandes gestores de esta versión de la vocación independentista del Uruguay, que desdibujaba la historia para crear una tradición de la diferencia allí donde ésta no había existido. De este modo, dotaba a la nación de una gesta heroica libertadora que pasaba a inaugurar la galería de símbolos nacionales, gesta que además la diferenciaba de lo argentino (De Torres 2008: 85).

Zorrilla de San Martín fue un referente cultural de la identidad nacional, uno de sus publicistas (Altamirano 2008). Sus obras literarias crearon un relato nacional para desarrollar la conciencia nacional en torno a una representación hispana del país (un Uruguay de raza blanca, habla española y cultura occidental).También lo hicieron sus discursos públicos en general, como los estudiados en este trabajo, en los que además de su catolicismo aparecen otras dos líneas centrales de su pensamiento: el hispanismo y el patriotismo.

\section{LAS REPRESENTACIONES SOCIOLINGÜÍSTICAS NACIONALISTAS}

Zorrilla de San Martín asignó a la lengua un lugar en sus reflexiones sobre la identidad nacional. En sus discursos, el español se representa como un vínculo con España para perpetuar una identidad hispánica común. Se preocupó por crear un carácter nacional (Rocca 2000) que diferenciara a Uruguay de España y el resto de los países hispanoamericanos, pero sin perder el vínculo y la identidad hispanos (Asencio 2004). Para ello construyó y difundió en sus discursos públicos dos representaciones nacionalistas en las que la lengua ocupa un lugar importante: la nación hispánica y la nación subtropical atlántica. Con la primera denominación defendía el vínculo de Uruguay con España por medio de la lengua y las tradiciones comunes; con la segunda, la particularidad lingüística y cultural de la nación uruguaya en oposición a Brasil y Argentina.

\subsection{LA NACIÓN HISPÁNICA}

En sus discursos, Zorrilla de San Martín argumentó que la independencia política de las naciones americanas no conllevaba su independencia religiosa, cultural o lingüística. Para ello apeló a un concepto de nación en el que se 
observa la influencia de Renan (1987 [1882]), como puede reconocerse en la siguiente cita $^{7}$ :

Yo hablo de la entidad humana, de la nación hispánica. Una nación es algo así como una humanidad en la humanidad, es un alma, un principio espiritual que informa los hechos encadenados, que amalgama las sangres, que ata en haces a los hombres, y los empuja a través del tiempo y del espacio, de las tierras y de los mares; es una herencia de recuerdos, aceptada por un acto colectivo instintiva perpetuamente renovado; es... en fin, yo no sé lo que es, señores, ni quiero saberlo en este momento definirlo; me basta con sentirlo intensamente, al sentir la respiración de un gran ser colectivo que se alza sobre todo esto, y que me parece escucha las palabras que suben de mi corazón, como si recibiera el incienso que sube desde una ascua; yo sé que, como esos grandes ríos que se derraman en el mar, y corren muchas leguas sin confundirse con él fluyen las nacionalidades por entre el mar de la humanidad, determinadas corrientes en que reverbera el sol. (Zorrilla de San Martín 1965a [1892]: 45).

Contrario a lo que podría suponerse, Zorrilla de San Martín no apelaba al concepto de nación para legitimar las fronteras políticas del Estado-nación uruguayo sino por el contrario lo usaba para referirse a una comunidad supraestatal en torno a lo hispano que tenía como centro a España.

En un discurso pronunciado en el Ateneo de Madrid (publicado en El bien público ese mismo año en dos oportunidades) expresaba los vínculos de lengua, "sangre", religión y tradiciones que unían los países hispanoamericanos a España, haciéndolos partícipes de la misma comunidad:

Si por la ley providencial se pueden y es posible romper vínculos políticos, no pueden romperse ni se romperán jamás los de la sangre, los de la fe, los de la lengua y los de las tradiciones y glorias que nos son comunes y constituyen nuestro orgullo conjuntamente con las demás glorias nacionales (Zorrilla de San Martín 1965b [1892]: 39, 1892a, 1892b).

7 Dice Renan: "Una nación es un alma, un principio espiritual. Dos cosas que no forman sino una, a decir verdad, constituyen esta alma, este principio espiritual. Una está en el pasado, la otra en el presente. Una es la posesión en común de un rico legado de recuerdos; la otra es el consentimiento actual, el deseo de vivir juntos, la voluntad de continuar haciendo valer la herencia que se ha recibido indivisa" (1987 [1882]: 82).

Sobre la influencia de Renan en los intelectuales uruguayos del último cuarto del siglo XIX, cfr. Ardao 1971. 
La ideología cristiana fue el fundamento del que se sirvió Zorrilla para justificar su posición (como se observa también en la cita anterior). Entendía que el vínculo filial de lengua, sangre, religión y costumbres entre España y sus excolonias respondía a una ley divina, y por lo tanto, era irrenunciable:

No es posible violar las leyes naturales, que son leyes de Dios; las Repúblicas hispanoamericanas tienen aún su madre en el continente europeo, y, si necesitan, como siempre necesitarán, un puesto de reunión en aquel mundo, ese no puede ser otro que la vieja casa paterna, esa simpática tierra española, en que hallarán su lengua, su religión, sus costumbres, su carácter y sus anhelos (Zorrilla de San Martín 1900a).

La salvaguarda de la "nación hispánica" fue la principal preocupación de Zorrilla de San Martín. Para ello apeló a los referentes tradicionales de los discursos nacionalistas: España y América estaban unidas -y debía cuidarse que continuaran estándolo- por la raza, la fe, las tradiciones y la lengua comunes, cuestión que no impedía sin embargo la independencia de cada Estado que integraba la gran familia hispánica (en la que España era la "madre patria" y los países hispanoamericanos sus hijos):

Yo creo firmemente que existe [...] una gran nación, o si queréis, una gran familia hispánica, que [...] posee, en la comunidad de lengua, de religión, de costumbres, de tradiciones, un elemento de una influencia tal en la actividad funcional del organismo del hombre, que bien puede influir en este mismo modificándolo, y constituir esa fuerza, o dinamismo, o como queráis llamarle, que reduce una pluralidad originaria a una unidad sociológica, sin menoscabar la personalidad independiente de las unidades libres que componen la primera (Zorrilla de San Martín 1893, en Palomeque 1992: 52).

La nación hispánica es asimismo descrita en términos metafóricos, como un coloso cuya cabeza es España, colocando también en esta representación a la "madre patria" como referente y líder de dicha comunidad: "sea ahora España la cabeza, el cerebro, el pensamiento; palpite en América el corazón" (Zorrilla de San Martín 1965b [1892]: 39).

La lengua común desempeñaba para Zorrilla un rol particularmente relevante en el mantenimiento de la identidad hispana. En tanto vehículo de la fe y las tradiciones españolas, en la propia lengua castellana estaba la nación hispánica, el "espíritu español”. O, dicho de otro modo, la nación hispánica era un principio espiritual (Renan1882 [1987]) cuyo centro era la lengua:

El lenguaje es, para un pueblo, lo que la sangre para un organismo; como ésta determina la constitución en el hombre, aquél determina el 
temperamento en una nación, sus tendencias, su carácter"; "con el idioma, [España ha legado a América también] el espíritu español que lo informa y vivifica (Zorrilla de San Martín 1965c [1892]: 84).

El "espíritu español" heredado de la "madre patria" generaba un vínculo "filial", de "sangre" entre españoles e hispanoamericanos y daba lugar a la actitud de "orgullo" de pertenecer a la misma "gran raza" a la vez que despertaba la conciencia de compartir los mismos antepasados y el deseo de defender la herencia de "fe", "lengua" y "costumbres" cuando estas se vieran amenazadas:

No es, por consiguiente, un sentimiento del corazón el que nos hace reclamar la unión de sangre con España; es un sentimiento de orgullo. Es cierto que no es extraño, señores, que yo manifieste mi amor a España, cuando siento en mi corazón los ecos de las primeras plegarias oídas en el regazo materno, porque allí las madres arrullan a sus hijos con los mismos cantos con que a vosotros os arrullan vuestras madres. No es extraño que yo, si siento ofender el nombre de España, sienta un impulso irresistible a salir a su defensa, porque entonces me parece sentir que se mueve el polvo de mi sangre en la tumba veneranda de mis abuelos reclamándome imperiosamente el santo tributo filial (Zorrilla de San Martín 1892a). España siempre la misma; siempre el gran pueblo, la gran raza. [...]. Llega hasta nosotros el eco solemne de una multitud que habla nuestra lengua y en nuestra lengua pide guerra porque ha creído ver ofendido su pabellón ${ }^{8}[\ldots]$.

América estará siempre al lado de España, porque no puede menos de estarlo, porque hasta el orgullo de raza estrecha y vigoriza los vínculos que nos ligan a la antigua metrópoli (Zorrilla de San Martín 1885).

Entendía, además, que en la medida en que España era el centro de la comunidad hispánica, de su progreso dependía el porvenir de la comunidad misma, por lo que proponía que los países hispanoamericanos favorecieran la prosperidad de España, en particular en la difusión de la lengua española, como modo de asegurar su propia existencia:

Los pueblos hispanoamericanos tienen un interés evidente, no solo moral sino también material en que España adelante en importancia e influencia

8 Se refiere al incidente diplomático ocurrido en 1885 entre España y Alemania como consecuencia de la ocupación alemana de Yap (una de las Islas Carolinas, entonces en posesión de España), que dio lugar a que la población y algunos militares en España reclamaran la guerra entre ambos países. 
en el concierto de las naciones europeas. Su adelanto es, en gran parte, el nuestro, porque es el progreso de nuestra lengua, y de nuestro espíritu, por consiguiente. [...].

Las hijas de la América española, por ley inevitable, y a menos de querer suicidarnos matando nuestro verbo, tenemos que anhelar la difusión de la lengua de Cervantes, tenemos que desear la prosperidad de España y debemos contribuir a ello en cuanto de nosotros dependa (Zorrilla de San Martín 1900a).

El discurso de la "nación hispánica", del "espíritu español" que cristaliza en la lengua castellana se inserta a su vez en la tradición del romanticismo alemán de fines del siglo XVIII y retoma entonces la concepción de nación de autores como Herder (1744-1803) y Humboldt (1767- 1835) que entendían que la lengua era el espíritu de la nación (Menze 2003, Hobsbawm 1992). Se apoya, además, en dos representaciones que sostienen al mismo tiempo una representación purista del español, necesaria también al discurso de la unidad lingüística y cultural entre España y América: el lenguaje como expresión del pensamiento y el lenguaje como organismo vivo 9 (Oroño 2015).

Para Zorrilla de San Martín cuidar la uniformidad del español era esencial para que la ideas que por él se transmitieran fueran claras. La unidad de lengua habilitaba la claridad del pensamiento:

El lenguaje es un sistema de signos arbitrarios que, sin uniformidad etimológica y usual, contribuirá poderosamente a confundir las ideas y a hacer fugaces las obras literarias, dada la íntima unión que en tales obras existe entre fondo y forma (Zorrilla de San Martín 1884b).

Según Zorrilla, las “incorporaciones” a la lengua común debían realizarse "sin adulterar su genio ni romper su unidad científica" (Zorrilla de San Martín 1965c [1892]:100). Destacaba como particularmente peligroso la incidencia de estas incorporaciones en la sintaxis del español, la "esencia", "el alma" del idioma, que aportaba la estructura, la "lógica", la "proporción" en la lengua, sobre la que el vocabulario se insertaba de forma más o menos cambiante:

\footnotetext{
9 La concepción organicista de la lengua, muy frecuente en autores del siglo XIX, fue propuesta por el gramático alemán August Schleicher (1821-1868), tomando como modelo los métodos en auge de las ciencias naturales. Esta concepción de la lengua como un organismo que responde a sus propias lógicas internas de desarrollo, independientes de la voluntad humana, desvincula a la lengua de la historia de las sociedades como acontecer político.
} 
La influencia de [otras lenguas cultas modernas] sobre nuestra lengua común $[. .$.$] puede serle perjudicial:[...] muy perjudicial, cuando, no sólo$ destierra esos vocablos, sino que, introduciendo sonidos y signos gráficos contrarios al genio de la lengua, y hasta a la disposición orgánica de los que la hablan, y, sobre todo, atacando la estructura sintáctica, que es el alma del idioma, introduce en éste el germen de la corrupción y de la muerte (Zorrilla de San Martín 1965c [1892]: 100).

Y yo entiendo por lengua española no tanto el vocabulario, que puede y debe ser constantemente enriquecido y adaptado al medio en que se emplea, cuando la sintaxis que es, en las lenguas, lo que la circulación de la sangre en el organismo: sintaxis es esencia, proporción, lógica, vida. Y todo eso es belleza (Zorrilla de San Martín 1899).

Para Zorrilla de San Martín la sintaxis era entonces la responsable de mantener la unidad de lengua.

Le preocupaba especialmente la influencia de la literatura y la lengua francesas en la lengua y la literatura castellanas, no solo en la sintaxis sino en el léxico:

Deploramos el ver ya que una preciosa locución ha sido abandonada para ser sustituida por un galicismo insulso y deficiente; ya que un giro grandilocuente y expresivo del divino Calderón ha sido transformado por la tontísima hispanofobia en una frase enteca y almabicada que trasciende a alizcle o patchouli; ya que aquel vigor, aquella varonil energía del lenguaje del romancero o del de los autores del siglo de oro, en que ha bebido su inspiración el mundo durante dos siglos, se está transformando en una especie de capa de estudiante en manos de los que reniegan de las glorias literarias de la madre patria sin conocerlas, y sin sospechar siquiera lo que es la lengua castellana, la única quizá en que no pierde su energía a imprecación de un héroe caballeresco, ni su entereza al anatema de un mártir, ni sus alas la plegaria de una virgen (Zorrilla de San Martín 1884a).

La lengua castellana era concebida como el molde de la literatura hispana; el instrumento que la expresaba. Zorrilla de San Martín proponía como ideal de lengua el castellano y la literatura "del siglo de oro", "de Calderón", "del romancero". Por eso discutía con sus contemporáneos que "renegaban" de ella y veían en la incorporación de galicismos y giros lingüísticos del francés la necesaria renovación lingüística y literaria para crear una nueva noción de literatura.

Mientras que Zorrilla de San Martín, como buen hispanófilo, buscaba restaurar un ideal de pureza de la lengua, desde la generación del 40 (Zum Felde 1967) y con la influencia del español Mariano José de Larra, 
comenzaron a romperse los cánones neoclásicos y el conservadurismo lingüístico en la literatura escrita en Uruguay (Rocca 2003) ${ }^{10}$. De todos modos, Zorrilla entendía que la salvaguarda de la unidad del español "no pugna en manera alguna, con el desarrollo progresivo, natural y científico, del organismo vivo del idioma", aunque debía ser controlado para "armonizar el crecimiento con la existencia, el movimiento con el orden, la autoridad y el uso con la ciencia y con la lógica" (Zorrilla de San Martín 1884b).

Es decir que aunque proponía como molde lingüístico y literario el español del siglo de oro, reconocía la estabilidad flexible (Garvin y Mathiot 1974) como un rasgo inherente a las lenguas y aceptaba la actualización o "desarrollo" del castellano, que caracterizó como "progresivo, natural y científico", por ejemplo mediante incorporaciones o cambios a nivel de vocabulario, como se ha indicado más arriba. Se trata de todos modos de una posición conciliadora, congruente con su función de académico correspondiente de la RAE ${ }^{11}$.

El discurso de Zorrilla de San Martín muestra la tensión política del momento histórico en que se produjo. El reconocimiento de que la lengua es variable y cambia adquirió una alta carga simbólica en los procesos de construcción de las identidades nacionales hispanoamericanas (Del Valle y Gabriel-Stheeman 2004), y está presente tanto en la posición hispanófila de Zorrilla de San Martín como en la de los americanistas de la generación del 40 y sus sucesores. Subyace la cuestión de la unidad/ fragmentación del español y la discusión acerca de qué cambios admitir, y quién y cómo podía realizarlos y encauzarlos, esto es, quién tenía la autoridad para planificar y en qué residía esa legitimidad.

En este sentido, Zorrilla de San Martín asignó un rol destacado a la literatura. Los literatos, a través del estudio de la lengua, del conocimiento de su gramática y de los autores clásicos podrían hablar el castellano con pureza y propiedad, con lo cual perpetuarían su obra y con ella el espíritu de la nación hispánica (Oroño 2015):

10 Aunque Rocca (2003: 74) señala que "si la literatura que se hace en estas tierras necesita ser renovada, y en buena medida galicizada - como Larra lo hizo con la castellana de España-, será por mediación de Larra y no del original francés, porque antes que nada era necesario defender la lengua castellana como patrón, por la necesaria dimensión social -y por lo tanto particular- de una literatura que se refleja en la pertenencia a un común universo cultural castellano, que cifra en la lengua la ideología central de esa pertenencia configuradora de costumbres y mentalidades semejantes".

11 En el discurso que da en 1892 con motivo de la celebración en Madrid del Congreso Literario Hispanoamericano, titulado "La lengua castellana" (Zorrilla de San Martín 1965c [1892]), Zorrilla desarrolló su posición al respecto (cfr. Caballero 1985 y Vásquez 2008). 
No sólo de pan vive el hombre ni tampoco las naciones. No han sido las riquezas las que han sobrevivido a los pueblos extinguidos: han sobrevivido las artes, las letras [...].

Hablamos castellano y los hombres de letras, para ser tales, deben comenzar por hablar con pureza y propiedad, por estudiar la lengua, por conocer los clásicos, y previo estudio profundo de la gramática, adquirir una elocución castellana que someterse pueda a la crítica y al estudio (Zorrilla de San Martín 1884b).

En la medida en que entendía que el rol de los literatos era fundamental en el mantenimiento del modelo de ejemplaridad lingüística castellano, tenía una actitud crítica hacia los que no lo respetaban:

No me diga un escritor o un poeta americano que su propósito al hablar o escribir mal es el de reformar la lengua española, si antes no me demuestra prácticamente que la conoce. [...]

Para mí es indiscutible: el noventa y nueve por ciento de los literatos americanos que afirman que ellos escriben en americano, sólo quieren decir con eso que no han estudiado gramática; que no saben el español, ni el francés, ni el tupí, ni nada; que van a la buena de Dios en lo que a lengua se refieren. Eso en cuanto a la materia en que el americano ha de modelar su obra artística.

En cuanto a la forma de ésta, es para mí muy accidental, y creo que pierden el tiempo los americanos que se esfuerzan en buscar la originalidad en el empleo de ritmos inauditos y de raras combinaciones métricas, o en los recursos de la orfebrería literaria hoy tan en boga.

[...] No malgastemos nuestro esfuerzo en buscar formas exóticas; concentrémoslo a mirar bien, con intensidad nuestra naturaleza, nuestro espíritu, nuestros tipos, nuestro origen y nuestro destino. Y cuando hayamos sorprendido una nota nueva, característica, démosla con ingenua sencillez, en buen castellano y en forma sobria y dura (Zorrilla de San Martín 1899).

En definitiva, con la representación de nación hispánica, Zorrilla de San Martín construyó discursivamente una identidad hispánica común que unía a España con el resto de los países hispanohablantes, incluyendo a Uruguay, que no se contradecía sin embargo con la soberanía política del país, porque para él "¿por qué la soberanía ha de ser incompatible con la voz del corazón y de la sangre?" (Zorrilla de San Martín 1900a).

Con la expresión metafórica la "sangre espiritual", Zorrilla se refería precisamente a los referentes identitarios constitutivos para él de la nación hispánica, y que ya han sido mencionados: la lengua, la religión, las tradiciones, la historia y la educación comunes. El conjunto de estos 
elementos eran los contenidos que demarcaban las fronteras de la nación hispánica ${ }^{12}$, creando un "medio ambiente social interno" uniforme, "un nudo subconsciente", una unidad espiritual, de "corazón", que se superponía al trazado de las fronteras políticas de los diferentes países hispanoamericanos:

¿Qué importa, señores, al lado de ese nudo subconsciente que nos une, que importa la ruptura de los vínculos políticos que nos unieron? ¿La recordamos acaso? [...] Ciertamente que no.

$\mathrm{Y}$ es porque las grandes y providenciales desmembraciones políticas, que pudieron en un día trazar nuevas fronteras en el mundo hispánico distribuyéndolo en nuevos estados, no tuvieron ni podían tener la facultad de establecer separaciones en la sangre, entendiéndose por tal, no tanto la sangre material que ha sido llamada el medio ambiente interior del cuerpo, y forma su idiosincrasia o temperamento, cuanto la sangre espiritual, ese medio ambiente social interno formado por la lengua, la religión, la educación, la común historia, las tradiciones comunes. En esto, señores, no se han trazado nuevas fronteras entre españoles y americanos; para ello hubiera sido necesario abrir surcos profundos en el corazón, y un surco en el corazón es la muerte (Zorrilla de San Martín 1893, en Palomeque 1992: 52).

\subsection{LA NACIÓN SUBTROPICAL ATLÁNTICA}

Zorrilla de San Martín elaboró una representación de los orígenes del Estadonación uruguayo -que Sansón (2006: 164) ubica dentro de la "escuela" historiográfica "nacionalista" defensora de la "tesis independentista clásica"-. Se preocupó por construir un sustento teórico para explicar la soberanía política del país en el que el providencialismo cristiano es central. La idea de que la historia humana responde al mandato de una ley divina, de que en última instancia Dios es el verdadero protagonista y sujeto de la historia, y que el hombre es solo su instrumento (presente también en la representación de la nación hispánica como se ha observado en el apartado

12 Los conceptos de contenidos y fronteras son usados por Barth (1976), quien se refiere a la identidad étnica. Su propuesta sin embargo puede aplicarse a otros procesos de construcción identitaria como el que Zorrilla de San Martín se esfuerza por construir en sus discursos sobre la nación hispánica. 
anterior) es el eje de la argumentación sobre la existencia de la nación subtropical atlántica ${ }^{13}$.

Así, para Zorrilla de San Martín, "la ley elemental que preside a la formación de las naciones" es una "ley superior a las formas y aún a la voluntad de los hombres muchas veces, y que Dios impone a los agrupamientos de hombres en forma de instinto heroico que todo lo arrolla" (Zorrilla de San Martín 1900b). "Las patrias [...] son primeramente una materia cósmica luminosa, un instinto que brota de leyes misteriosas, leyes étnicas, geológicas, sociológicas, históricas, todas ellas emanadas del Supremo Legislador" (Zorrilla de San Martín 1965d [1902]: 88).

Ibáñez (1956) reconoce en la concepción providencialista de la historia que guiaba el trabajo de Zorrilla de San Martín dos influencias fundamentales: la de San Agustín (354- 430), autor fundacional de esta corriente, y la de Bossuet (1627- 1704). Así como Zorrilla "interpreta el proceso humano como el cumplimiento de una ley divina" (Ibáñez 1956: 91), tanto San Agustín en su Ciudad de Dios como Bossuet en su Discurso sobre la historia universal explican que "Dios es quien rige, con su providencia, los hechos de los hombres y el curso de la historia" (Gómez Forner 2016: 197). Pero mientras que en San Agustín el providencialismo es el transcurrir del tiempo direccionado según el plan divino, en Bossuet el providencialismo está acompañado por un determinismo que justifica la necesidad del orden y la legitimidad de los poderes establecidos (Gómez Forner 2016). El providencialismo de Zorrilla de San Martín entonces no solo explicaba la creación del Estado- nación uruguayo en términos divinos sino que es una herramienta que le permitiría legitimar el orden impuesto. Aunque no es objeto de este trabajo, esto puede observarse claramente en su explicación sobre la colonización de América y su concepción sobre la población originaria de esta región (cfr. Caballero 1985).

Otro elemento central en su representación sobre la nación subtropical atlántica fue el rol destacado que le atribuyó a la figura del héroe, que actuaba como mediador entre el pueblo y Dios, "intérprete del alma colectiva y órgano de la voluntad de Dios" (Ibáñez 1956: 91).

13 Esta teoría ya aparece en la tercera edición de La leyenda patria (1883), en la que habla de "fronteras demarcadas/ por la mano de Dios", y se desarrolla plenamente en La epopeya de Artigas (1910) (Ibáñez 1956). 
Según Zorrilla de San Martín, Dios indicó al héroe Artigas (y luego a los Treinta y Tres Orientales) ${ }^{14}$ cómo proceder para alcanzar "una nueva patria independiente":

Artigas [...]. Él fue el primero que sintió la ley providencial que marcaba una nueva patria independiente que, siendo subtropical, era al mismo tiempo atlántica $[\ldots]$

Así sintió la patria nuestro viejo Artigas; recibió un mensaje de lo alto; oyó y cumplió un decreto de Dios. [...]

Los Treinta y tres hijos de Artigas [...] sabían por instinto cuáles eran los límites marcados por Dios a la patria atlántica subtropical.

[...] Nuestros héroes fueron los gloriosos ejecutores de los decretos de Dios (Zorrilla de San Martín 1900c).

Para Zorrilla de San Martín, Artigas, al igual que el profeta bíblico, guió al pueblo oriental en la lucha por la construcción de la nación independiente. Y lo mismo haría Lavalleja, guiando a los Treinta y Tres Orientales:

Artigas se ha ido, señores, y se ha ido para no volver; se ha puesto en los horizontes de la patria. Esta parece borrarse para siempre en la mirada que su profeta le dirige al transponer la frontera. La soñada patria atlántica subtropical es sólo una vasta soledad, atada a las regiones del trópico con cadenas de hierro; una lengua extraña se habla oficialmente en nuestro altivo Montevideo [...]. Lavalleja es el elegido, es el ungido; Lavalleja es el hijo primogénito de Artigas. Tiene ya en la frente la luz profética inconfundible; el ascua ardiente lo ha tocado en la boca. Con sólo montar a caballo y presentarse en la patria, ostentando su mensaje luminoso, la patria lo reconocerá, y lo seguirá como siguió al viejo Artigas: lo seguirá porque sí (Zorrilla de San Martín 1965d [1902]: 93).

Zorrilla de San Martín elegiría finalmente como acto fundacional de la nacionalidad uruguaya la Cruzada Libertadora (cfr. Rocca 2000, De Torres 2008).

14 José Gervasio Artigas (1764-1850) fue un militar rioplatense que actuó durante la Guerra de la Independencia de las Provincias Unidas del Río de la Plata y que se destacó por defender el federalismo Recibió los títulos de "Jefe de los Orientales" y "Protector de los Pueblos Libres". Es el máximo prócer de Uruguay. Los Treinta y Tres Orientales es el nombre con el que históricamente se conoce a los hombres liderados por Juan Antonio Lavalleja y Manuel Oribe que, en 1825, emprendieron una insurrección desde lo que hoy es la Argentina, para recuperar la independencia de la Provincia Oriental (territorio que comprendía lo que hoy es Uruguay y parte del actual estado brasileño de Río Grande del Sur), en ese momento bajo dominio brasileño. 
Zorrilla de San Martín combinó su providencialismo con una concepción individualista del acontecer histórico, centrada en la figura del "héroe", que explícitamente tomó de Carlyle (1795- 1881) (cfr. Zorrilla de San Martín 1965e [1902]) y asoció a la figura de Artigas. Carlyle sostiene que el avance de la civilización se debe a los hechos de individuos excepcionales y no de las masas. Sin "héroes" no habría historia. Así, la verdadera iniciativa se reserva para esa minoría selecta. La masa debe someterse a la voluntad de esos elegidos que son los caudillos natos (Carlyle en Cassirer 1968).

La concepción del heroísmo como actividad superior y reveladora de nuevos destinos de Carlyle cuajó muy bien con la concepción providencialista de Zorrilla: el héroe se convirtió en un enviado providencial (Pivel Devoto 1963, Zum Felde 1967). Esta concepción elitista de la acción humana encajaba perfectamente con la explicación divina y determinista de la creación de las naciones usada por Zorrilla de San Martín para explicar la existencia de Uruguay como nación independiente. En resumen:

En el pensamiento de Zorrilla de San Martín las patrias eran un instinto nacido de leyes históricas y sociológicas emanadas de una voluntad suprema; un hombre surgido de la entraña del pueblo acaudillaba esos instintos y luego era la multitud la que, identificando su alma colectiva con el alma del héroe, imponía al fin su voluntad (Pivel Devoto 1963: XXVII).

La existencia de una nación independiente en el actual territorio uruguayo se justificaba además para Zorrilla en términos "geológicos" y "etnológicos":

La metrópoli de Montevideo con el territorio oriental tenían que ser independientes, mal que pesara a la más expresa voluntad de los hombres; no podía ser argentina ni brasilera; brasilera, porque, aunque geológica y etnológicamente, su territorio pertenecía a la formación geológica del atlántico, sociológicamente pertenecía al virreinato español, étnicamente estaba separada del resto de los dominios del rey de España por la cuenca de los grandes ríos que dividen en dos regiones diferentes el continente americano (Zorrilla de San Martín 1900b).

[Artigas] fue el primero que vio, con la clarividencia del genio, cómo se desprenden los grandes ríos meridionales de las entrañas de América, para venir a desembocar en el Plata, formando dos regiones distintas, dos patrias hermanas pero diferentes, a ambos lados de esos ríos; él comprendió, o mejor dicho, sintió en el fondo de su ser, que, por una ley no sólo sociológica sino también geológica y etnológica, este pedazo privilegiado del suelo americano tenía que ser territorio de una patria independiente; porque si por ley sociológica estábamos unidos, por la lengua y las tradiciones españolas, a nuestros hermanos de allende el 
Plata que tienen por núcleo el levantamiento geológico de los Andes, por ley étnica pertenecíamos a la formación atlántica; y si esta nos unía etnológicamente a las antiguas colonias portuguesas de ellas nos separaban, no solo las tradiciones de lengua y de costumbres, no sólo la rivalidad secular de nuestra posición geográfica, que nos separa de los grandes dominios del trópico, y nos marca como el núcleo inconmovible de los pueblos atlánticos subtropicales, o de la zona templada de América (Zorrilla de San Martín 1900c).

Nuestra patria, señores, la república atlántica subtropical [...]. Trozo del continente separado de la región tropical por el clima, y segregado también de la región andina por la formación geológica, tenía que ser el núcleo de una nacionalidad independiente. Esa es la armonía. [...]. Él [Artigas] fue el primero que sintió la ley providencial que decretaba la existencia de una patria independiente en este territorio que bañan el Uruguay, el Plata y el Atlántico: una patria que siendo subtropical, era al mismo tiempo atlántica. [...] Él comprendió, o más bien dicho, sintió, en el fondo de su ser, cómo, por una ley, no sólo sociológica sino también geológica y etnológica, este pedazo de suelo americano tenía que ser el territorio de una patria independiente. Porque si según las leyes sociológicas, estábamos unidos, por la lengua y las tradiciones españolas, a nuestras hermanos de allende el Plata, que tienen por núcleo geológico el levantamiento de los Andes, según las leyes étnicas perteneceríamos a la formación Atlántica del Brasil. Y si éstas nos unían etnológicamente a las antiguas posesiones portuguesas, de ellas nos separaban, no sólo las tradiciones de lengua y de costumbres, no sólo la rivalidad secular de los dos pueblos descubridores, sino también nuestra posición geográfica, que nos separa de los dominios del trópico, y nos marca como el núcleo inconmovible de los pueblos atlánticos subtropicales de la América Meridional.[...] Así sintió a nuestra patria el viejo Artigas; recibió una relevación de lo alto; oyó y cumplió un decreto de Dios (Zorrilla de San Martín 1965d [1902]: 88-90).

Zorrilla de San Martín reconocía en la naturaleza el testimonio de la voluntad divina. Así, para establecer los fundamentos eternos de la existencia de Uruguay como pueblo independiente y soberano, recordaba que la línea divisoria trazada por el papa Alejandro VI al distribuir la América del Sur entre España y Portugal se ajustaba a la estructura natural del continente, constituido por dos partes: una, la "formación geológica atlántica" (recortada por el océano Atlántico y la cuenca del río Amazonas), que correspondía al imperio lusitano; otra, cuyo centro era el "levantamiento geológico de los Andes" (recortada por el océano Pacífico y los ríos Paraná, Paraguay y Uruguay), que correspondía al imperio español. 
Dentro de estos dos espacios geográficos, Uruguay emergía, para Zorrilla de San Martín, como una entidad diferenciada de los países vecinos por la combinación de sus rasgos "geológicos" y "etnológicos" con sus particularidades lingüísticas y culturales.

Entendía que Uruguay compartía con Brasil los rasgos "geológicos" y geográficos por pertenecer a la "formación geológica atlántica", pero no la lengua portuguesa y las tradiciones lusitanas. Tenía en común con Argentina los rasgos "sociológicos", esto es, la lengua española y las tradiciones hispanas, pero se separaba de ella por no pertenecer al "levantamiento geológico de los Andes". Este cruce de caracteres hacía a la particularidad del pueblo oriental en tanto lo que oficiaba de parteaguas era la lengua.

\section{CONSIDERACIONES FINALES}

En la construcción de las representaciones sociolingüísticas nación hispánica y nación subtropical atlántica confluyeron dos ideologías que se disputaban el monopolio de la representación hegemónica de la realidad desde mediados del siglo XIX en Hispanoamérica: el cristianismo y el hispanismo. Zorrilla de San Martín fue uno de los pocos intelectuales uruguayos que defendía ambas posturas, por lo que aprovechando su capital simbólico (Bourdieu 2001) en sus discursos públicos siempre que pudo difundió representaciones vinculadas con estas posiciones para influir en la opinión pública y producirfijar legitimaciones. Era un modo de participar en la disputa por el liderazgo cultural y lingüístico de los católicos hispanófilos.

La cuestión de la lengua aparece en sus discursos no como tema central sino a propósito de problemas político-culturales: fundamentalmente la formación de la literatura nacional y el mantenimiento del cristianismo como sistema filosófico (Ardao 1971), en el marco de su preocupación por defender la independencia política de Uruguay sin romper los vínculos culturales y lingüísticos con España. Para ello apeló al borramiento (Irvine y Gal 2000) o invisibilización tanto de las diferencias lingüísticas entre las variedades peninsulares del español y las americanas, como de la presencia de diferentes lenguas en Uruguay. En sus discursos no aludió ni a la existencia del portugués ni a la presencia de lenguas migratorias en el territorio uruguayo (aunque durante todo el último cuarto del siglo XIX la representación del portugués como amenaza a la identidad nacional tuvo una gran visibilidad con la reforma escolar iniciada en 1877 con José Pedro Varela (cfr. Oroño 
2016a, Barrios 2013). La lengua castellana se constituyó de este modo en representación icónica (iconización, Irvine y Gal 2000) tanto de la nación hispánica como de la nación subtropical atlántica.

De todos modos, la postura lingüística tradicionalista y conservadora de Zorrilla de San Martín no pudo imponerse. Su hispanismo sobrevivió en muchos discursos sociales (por ejemplo en el decreto de creación de la Academia Nacional de Letras de 1943, que reivindicaba la unidad de la lengua española y la acción prescriptiva para controlar el peligro de la fragmentación lingüística; cfr. Barrios 2011), pero matizado por la búsqueda del equilibrio entre mantener los vínculos con España y valorar lo propio. $\mathrm{Al}$ menos en el ámbito educativo los diferentes períodos históricos van mostrando una apertura a la aceptación de rasgos lingüísticos regionales (Oroño 2016b). En relación con su cristianismo, el positivismo se consolidó como corriente hegemónica en Uruguay a fines del siglo XIX con la reforma escolar vareliana (Ardao 1971, Araújo 1911). La religión fue desligada oficialmente de la educación en 1909 (Araújo 1911), y definitivamente de la órbita estatal con la Constitución de 1917, que estableció la separación entre la Iglesia y el Estado.

\section{REFERENCIAS BIBLIOGRÁFICAS}

Altamirano, Carlos (dir.). 2008. Historia de los intelectuales en América Latina. Volumen I: La ciudad letrada, de la conquista al modernismo. Madrid: Katz.

ANDERSON, BenEDICT. 1993. Comunidades imaginadas. Reflexiones sobre el origen y la difusión del nacionalismo. Buenos Aires: Fondo de Cultura Económica.

Araújo, Orestes. 1911. Historia de la escuela uruguaya. Montevideo: El siglo ilustrado.

Ardao, Arturo. 1971. Etapas de la inteligencia uruguaya. Montevideo: Udelar.

Asencio, PILAR 2004. Una frontera sociolingüística en el Uruguay del siglo XIX: lengua española e identidad nacional. Spanish in Context: 1, 2. 215-240.

2006. Temas de Sociolingüistica: Representaciones y norma lingüistica en Uruguay. Montevideo: Udelar. Serie Papeles de Trabajo.

Barrios, Graciela. 2009. Etnicidad y lenguaje. La aculturación sociolingüistca de los inmigrantes italianos en Montevideo. Montevideo: CSIC- Udelar (FHCE).

2011. La regulación política de la diversidad: academias de lenguas y prescripción idiomática. En Silvia Senz Bueno y Monserrat Alberte (eds.). El dardo en la Academia. Esencia y vigencia de las Academias de la lengua española. Vol I, pp. 591-619. Barcelona: Melusina.

2013. Language diversity and national unity in the history of Uruguay. En José Del Valle (ed.). A Political History of Spanish: The Making of a Language, pp. 197-211. Nueva York: Cambridge University Press.

Barth, Fredrik. 1976. Los grupos étnicos y sus fronteras. La organización social de las diferencias culturales. México: Fondo de Cultura Económica. 
Behares, Luis. 2007. Portugués del Uruguay y educación fronteriza. En Claudia Brovetto, Nicolás Brian y Javier Geymonat (eds.). Portugués del Uruguay y educación bilingüe, pp. 99-171. Montevideo: Administración Nacional de Educación Pública.

Bertolotti, Virginia y Magdalena Coll. 2012. Reflexiones sobre la lengua en América. En Alfonso Zamorano (coord. y ed.). Reflexión lingüistica y lengua en la España del siglo XIX: marcos, panoramas y nuevas aportaciones, pp. 443- 466. München: Lincom.

Bordoli, Domingo. 1961. Vida de Juan Zorrilla de San Martín. Montevideo, Concejo Departamental de Montevideo: Dirección de Artes y Letras.

Bourdieu, Pierre. 2001. ¿Qué significa hablar? Economía de los intercambios lingüisticos. Madrid: Akal.

2002. Campo de poder, campo intelectual. Itinerario de un concepto. Buenos Aires: Montressor.

Boyer Henri. 2003. De l'autre côté du discours. Recherches sur le fonctionnement des représentations communautaires. Paris: L'Harmattan.

Boyer, Dominic y Claudio Lomnitz. 2005. Intellectuals and Nationalism: Anthropological Engagements. Annual Review of Anthropology, 34. 105-120.

Burke, Peter. 2002. Historia social del conocimiento. Barcelona: Paidós.

Caballero, Milagros. 1985. "Juan Zorrilla de San Martín en la encrucijada del IV Centenario del Descubrimiento de América”. En Andalucía y América en el siglo XIX. Actas de las V Jornadas de Andalucía y América, pp. 104- 125. Sevilla: Universidad Hispanoamericana Santa María de la Rábida- CSIC.

Cassirer Ernst. 1968. El mito del Estado. México: Fondo de Cultura Económica.

CAETANo, Gerardo. 1992. Identidad nacional e imaginario colectivo en Uruguay. La síntesis perdurable del Centenario. En Hugo Achugar y Gerardo Caetano (comps.). Identidad uruguaya: ¿mito, crisis o afirmación?, pp. 75-96. Montevideo: Trilce.

Caetano, Gerardo, Roger Geymonat y Alejandro Sánchez. 2000. Dios y Patria. Iglesia Católica, nación y nacionalismo en el Uruguay del Centenario. En Gerardo Caetano (dir.). Los uruguayos del Centenario. Nación, ciudadanía, religión y educación (1910-1930), pp. 17-66. Montevideo: Santillana.

Del Valle, José (ed.). 2007. Lengua, ¿patria común? Ideas e ideologías del español. Madrid: Iberoamericana-Vervuert.

Del Valle, José y Luis Gabriel-Stheeman. 2004. Nacionalismo, hispanismo y cultura monoglósica. En José Del Valle y Luis Gabriel-Stheeman (eds.). La batalla del idioma. La intelectualidad hispánica ante la lengua, pp. 15-33. Madrid-Frankfurt: IberoamericanaVervuert.

De ToRres, María InÉs. 2008. La guerra de las palabras: escritura y política en el Río de la Plata. Montevideo: Banda Oriental.

Di Tullio, Ángela. 2003. Políticas lingüísticas e inmigración: el caso argentino. Buenos Aires: Eudeba.

Fishman, JoshUa. 1989. Language and ethnicity in minority sociolingüistic perspective. Clevelon- Philadelphia: Multilingual Matters.

Gallardo, Antonio. 1978. Hacia una teoría del idioma estándar. Revista de Lingüística Teórica y Aplicada: 16. 85- 119.

Garvin, Paul y Madeleine Mathiot. 1974. La urbanización del idioma guaraní. Problema de lengua y cultura. En Paul Garvin y Yolanda Lastra (comp.). Antología de estudios de etnolingüistica y sociolingüística, pp. 303-313. México: UNAM.

Gellner, ERNest. 1988. Naciones y nacionalismos. Madrid: Alianza.

Gómez Forner, Juan José. (2016) El pensamiento filosófico y político de Jacobo Benigno Bossuet. Tesis para obtener el grado de doctor, Universidad Complutense de Madrid. 
Halperin Donghi, T. 2013. Letrados y pensadores. El perfilamiento del intelectual hispanoamericano en el siglo XIX. Buenos Aires: Emecé.

Haugen, Einar. 2001. Dialeto, língua, nação. En Marcos Bagno (org.). Norma lingüística, pp. 97-114. San Pablo: Loyola.

Hobsbawm, ERIC. 1992. Naciones y nacionalismo desde 1780. Barcelona: Crítica.

IbÁÑEz, Roberto. (comp.). 1956. Originales y documentos de Juan Zorrilla de San Martín. Montevideo: Ministerio de Instrucción Pública y Previsión Social, Instituto Nacional de Investigaciones y Archivos Literarios.

Irvine, Judith y Susan Gal. 2000. Language ideology and linguistic differentiation. En Paul Kroskrity (ed.). Regimes of language: Ideologies, polities and identities, pp. 35-84. Santa Fe: School of American Research Press.

LAUXAR. 1955. Juan Zorrilla de San Martín. Montevideo: La Casa del Estudiante.

Menze, Clemens. 2003. Carácter nacional y lengua según Wilhelm von Humboldt. Introducción a los estudios vascos: 48,1. 33-49.

Milroy, James y Lesley Milroy. 1985. Authority in language. Investigating language prescription and standardization. Londres: Routledge y Kegan Paul.

Narvaja de Arnoux, Elvira y José Del Valle. 2010. Las representaciones ideológicas del lenguaje. Discurso glotopolítico y panhispanismo. Spanish in Context: 7, 1. 1-24.

NiÑo-MurCiA, MERCEDES. 1997. Ideología lingüística hispanoamericana en el siglo XIX: Chile (1840-1880). Hispanic Linguistics: 9, 1. 100-142.

OroÑo, Mariela. 2015. Las representaciones sociolingüísticas en José Pedro Varela y Juan Zorrilla de San Martín: primera aproximación. Revista Digital de Políticas Lingüísticas de la AUGM: 7, 7. 27-50

2016a. La escuela en la construcción de las fronteras culturales y lingüísticas en el Uruguay de fines del siglo XIX. Páginas de educación: 9, 1. 137-167.

2016b. El lenguaje en la construcción de la identidad nacional. Los libros escolares de lectura de Vásquez Acevedo, Figueira y Abadie-Zarrilli. Montevideo: Tradinco.

Piazza, Eduardo. 2011. En busca de la nación. Revista Encuentros Uruguayos: IV, 4. Disponible en www.encuru.fhuce.edu.uy/.

Pivel Devoto, Juan. 1963. Prólogo. En Juan Zorrilla de San Martín (1965), La epopeya de Artigas, pp. VII- XXXVIII. Montevideo: Ministerio de Instrucción Pública y Previsión Social.

Rama, CARLos. 1982. Historia de las relaciones culturales entre España y América Latina. Siglo XIX. México: Fondo de Cultura Económica.

Ramírez, Mercedes. 2001. Juan Zorrilla de San Martín. En Nuevo Diccionario de Literatura Uruguaya, pp. 326-328. Montevideo: Banda Oriental.

Renan, ERnest. 1987 (1882). ¿Qué es una nación? En Ernest Renan, Cartas a Strauss, pp. 55-86. Madrid: Alianza Editorial.

Rocca, Pablo. 2000. Los destinos de la nación. El imaginario nacionalista en la escritura de Juan Zorrilla de San Martín, Eduardo Acevedo Díaz y su época. En Hugo Achugar y Mabel Moraña (eds.). Uruguay: imaginarios culturales. Volumen I: Desde las huellas indigenas a la modernidad, pp. 241-258. Montevideo: Trilce.

2003. Poesía y politica en el siglo XIX (Un problema de fronteras). Montevideo: Banda Oriental.

SAnsón, Tomás. 2006. La Historia y los historiadores rioplatenses del siglo XIX. En Dante Turcatti y Tomás Sansón, Ensayos de historiografia latinoamericana y rioplatense, pp. 133-200. Montevideo: FHCE.

VÁzQuez, Graciana. 2008. La lengua española, ¿herencia cultural o proyecto políticoeconómico? Debates en el Congreso Literario Hispanoamericano de 1892. Revista Signos 4, 66. 81-106. 
Zimmermann, Klaus. 2008. Políticas lingüísticas e identidad: una visión constructivista". En

Ulrike Mühlschlegel y Kirsten Süselbeck (eds.). Lengua, nación e identidad: la regulación

del plurilingüismo en España y América Latina, pp. 21-40. Madrid: Iberoamericana.

Zorrilla de San Martín, Juan. 1884a. Rafael Calvo. El bien público. 27de enero de 1884. 1884b. Los amores de Marta. El bien público. 3 de julio de 1884.

1884c. Nuestro aniversario. El bien público. 1 de noviembre de 1884.

1885. Siempre el gran pueblo. El bien público. 1 de setiembre de 1885 .

1887. La Unión Ibero-Americana. El bien público. 7 de octubre de 1887.

1892a. Discurso pronunciado en la Unión Ibero-Americana. El bien público. 9 de

julio de 1892 .

1892b. El cerebro y el corazón. El bien público. 17 de setiembre de 1892.

1893. Congreso Pedagógico. En Agapo Palomeque (recop.) (1992). Personalidades

que han contribuido a la consolidación de la cultura y las estructuras educacionales, pp.

45- 56. Montevideo: Cámara de Representantes.

1899. "Concepto de literatura americana”. El bien público. 23 de agosto de 1899. 1900a. La madre patria. El bien público. 6 de abril de 1900.

1900b. 19 de abril. El bien público. 19 de abril de 1900.

1900c. La Patria Oriental. El bien público. 25 de agosto de 1900.

1965a (1892). El mensaje de América. En Conferencias y discursos. 1855- 1931.

Tomo I, pp. 41-52. Montevideo: Bertrán y Castro.

1965b (1892). Descubrimiento y conquista del Río de la Plata. En Conferencias y discursos. 1855-1931. Tomo I, pp. 3-40. Montevideo: Bertrán y Castro.

1965c (1892). La lengua castellana. En Conferencias y discursos. 1855-1931. Tomo

I, pp. 79-103. Montevideo: Bertrán y Castro.

1965d (1902). Lavalleja. En Conferencias y discursos. 1855- 1931. Tomo II, pp. 85-98. Montevideo: Bertrán y Castro.

1965e (1902). León XIII y la América Latina. En Conferencias y discursos. 1855 1931. Tomo II, pp. 99-129. Montevideo: Bertrán y Castro.

Zum Felde, Alberto. 1967. Proceso intelectual del Uruguay. Montevideo: Ediciones del Nuevo Mundo. 